\title{
Indoor Occurrence of the Ghost Ant Tapinoma melanocephalum (Hymenoptera: Formicidae) in Urban Homes in Korea
}

\author{
In Yong Lee', Seong Joon Park², Jang Hoon Seo ${ }^{3}$, Seobo Sim4, Jin-Hwan Kim5, Young Gon Gwon ${ }^{6}$, Tai-Soon Yong ${ }^{1, *}$ \\ ${ }^{1}$ Department of Environmental Medical Biology and Institute of Tropical Medicine, Yonsei University College of Medicine, Seoul 03722, Korea; \\ ${ }^{2}$ Department of Ecological Assessment, Bureau of Ecological Assessment, National Institute of Ecology, Seocheon 33657, Korea; ${ }^{3}$ Department of \\ Biomedical Laboratory Science, Shinhan University, Uijeonbu 11644, Korea; ${ }^{4}$ Department of Environmental and Tropical Medicine, School of \\ Medicine, Konkuk University, Chungju 27478, Korea; ${ }^{5}$ MiraeES Co. Ltd, Seongnam 13209, Korea; ${ }^{6}$ Eunonroach Co., Ltd., Gumi 39352, Korea
}

\begin{abstract}
The ghost ant Tapinoma melanocephalum is a common household pest worldwide. The present study examined the occurrence of the species in urban homes in Korea. During the period of September 2014 to January 2016, $T$. melanocephalum workers were collected from 58 homes at 29 different localities using bait traps with 10\% sugar solution. The species was widely distributed throughout urban homes at 29 different localities, and the indoor occurrence of $T$. melanocephalum was highest in Seoul (32.7\%) and metropolitan areas of Gyeonggi-do (Province) (29.3\%). The indoor incidence rate of $T$. melanocephalum peaked in September (22.8\%), remained moderate from October through April, and peaked again in May (15.7\%). In contrast, a low incidence was observed from June to August (7.0\%). The present study provides evidence that native ants, such as T. melanocephalum, are potential indoor pests of homes in Korea throughout the year.
\end{abstract}

Key words: Tapinoma melanocephalum, ghost ant, indoor pest, urban, Korea

The ghost ant Tapinoma melanocephalum (Fabricius, 1793) is a ubiquitous indoor and outdoor pest throughout much of the tropics and subtropics, and an increasingly common indoor pest in temperate regions (Europe, North America, China, and Japan). In colder climates, the species has been found in places with high humidity and temperature, such as apartments, restaurants, hospitals, and greenhouses [1-3]. Although T. melanocephalum does not sting and its bite is not painful, it can be a public health risk and can damage food. The species has been known since 1887; however, records of its occurrence have increased with the rise of globalization and global trade [4-7].

In Korea, the origin of indoor infestations by $T$. melanocephalum is not clear, but such infestations were first reported in 2005 [1]. There are up to 135 known species of ants in Korea [8], and 2 species, the Pharaoh ant (Monomorium pharaonis) and Asian needle ant (Pachycondyla chienesis), are considered

- Received 3 January 2017, revised 5 February 2017, accepted 12 February 2017.

*Corresponding author (tsyong212@yuhs.ac)

(c) 2017, Korean Society for Parasitology and Tropical Medicine

This is an Open Access article distributed under the terms of the Creative Commons Attribution Non-Commercial License (http://creativecommons.org/licenses/by-nc/4.0) which permits unrestricted non-commercial use, distribution, and reproduction in any

medium, provided the original work is properly cited. major urban pests $[9,10]$. The aims of the present study were to investigate the distribution and monthly incidence of T. melanocephalum. To our knowledge, this is the first investigation of T. melanocephalum in urban homes in Korea.

During the period of September 2014 to January 2016, invasive ants were collected from 58 homes by placing 3 bait traps with a $10 \%$ sugar solution on kitchen room for 1 day, and the homes were distributed among 29 localities, including Seoul (19), Inchon (3), Paju (1), Goyang (3), Gimpo (1), Anyang (2), Gwangmyeong (1), Seongnam (3), Suwon (1), Hanam (1), Guri (1), Uiwang (1), Ansan (1), and Pyeongtack (1) in Gyeonggi-do (Province), Goseong (1) in Gangwon-do; Asan (1), Cheonan (1), and Daejeon (1) in Chungcheongnam-do; Chungju (1) and Cheongju (1) in Chungcheongbuk-do; Jeonju (4) and Iksan (1) in Jeollabuk-do; Gwangju (1) in Jeollanamdo; Gumi (1), Andong (1), Daegu (1), and Gyeongju (1) in Gyeongsangbuk-do; and Jinju (1) and Busan (2) in Gyeongsangnam-do.

The collected ants were identified under a stereomicroscope. They were identified as T. melanocephalum workers (Fig. 1A). The ants were small (average $\geq 1 \mathrm{~mm}$ ). Their shapes were distinctly bicolored, with the head (except for the first 2 antennae segments) and mesosoma being dark brown to blackish-brown 

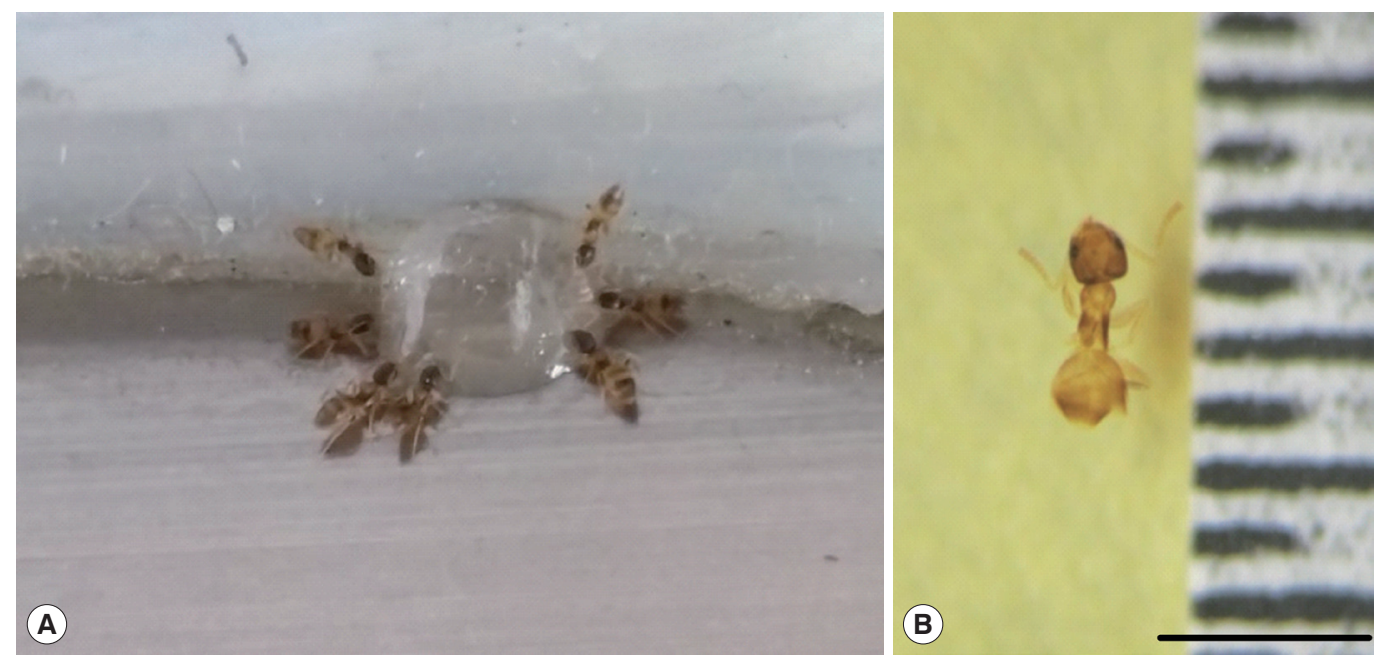

Fig. 1. Ghost ant (Tapinoma melanocephalum) workers. (A) T. melanocephalum at a bait trap with 10\% sugar solution. (B) Dorsal view. Scale bar $=1 \mathrm{~mm}$.

and the appendages, petiole, and gaster being milky white. The eyes were large, the antennae had 12 segments, the thorax was spineless, the gaster was hairless, and the abdomen had no stinger (Fig. 1B).

The indoor occurrence of T. melanocephalum differed by locality (Table 1). The results were higher in Seoul (32.7\%) and in Gyeonggi-do (29.3\%) than in Chungcheongnam-do (5.2\%), Chungcheongbuk-do (3.5\%), Jeollabuk-do (8.6\%), Jeollanamdo (1.7\%), Gyeongsangbuk-do (6.9\%), Gyeongsangnam-do $(1.7 \%)$, and Busan (3.5\%). No ghost ants were observed in the home in Goseong, Gangwon-do.

The indoor incidence rate of T. melanocephalum started to increase in September $(22.8 \%)$, remained moderate from October through April, and peaked again in May (15.7\%), whereas a low incidence was observed from June to August (Fig. 2). Therefore, $29.8,7.0,35.1$, and $28.1 \%$ of the total infestations were observed during the spring (March-May), summer (June-August), autumn (September-November), and winter (December-February), respectively.

The second half of the twentieth century and the beginning of the twenty-first century have witnessed important changes in ecology, climate, and human behavior that favor the development of urban pests. Most alarmingly, urban planners are now faced with the dramatic expansion of urban sprawl, whereby the suburbs of cities are exposed to the natural habitats of ticks, rodents, and other pests. In addition, many city managers now erroneously assume that pest-borne diseases are relics of the past [11], and globalization is increasing the spread of various vector-borne diseases and urban pests [12]. Ants live

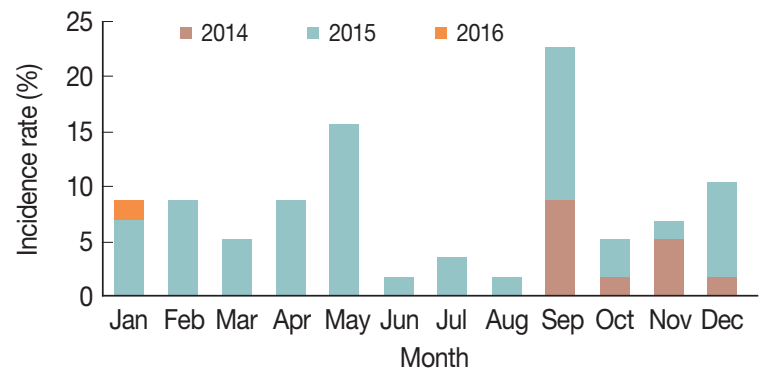

Fig. 2. Total monthly incidence rate of the ghost ant Tapinoma melanocephalum in urban homes from September 2014 to January 2016 in Korea.

with humans and are readily adapted to urban environments across the globe.

In the present study, the ghost ant T. melanocephalum was found to be widely distributed throughout urban homes at 29 different localities in Korea throughout the year. Therefore, it is clear that T. melanocephalum is a new indoor ant species in Korea. This species is known to transport pathogenic microbes [37], and in some people, contact with the ant can cause a slight, red irritation of the skin [13].

T. melanocephalum is similar to the Pharaoh ant Monomorium pharaonis in shape, and the 2 species are quite difficult to distinguish with the naked eye. However, T. melanocephalum workers can be easily identified by their extremely small size and peculiar color markings; moreover, T. melanocephalum workers possess only a single pedicel node, whereas M. pharaonis workers possess 2 pedicel nodes. M. pharaonis is a major indoor pest worldwide [9] that has an abdomen that is darker than its tho- 
Table 1. Indoor occurrence of the ghost ant Tapinoma melanocephalum in urban homes in Korea

\begin{tabular}{|c|c|c|c|c|c|}
\hline \multirow{2}{*}{ Locality } & \multirow{2}{*}{$\begin{array}{c}\text { No. of } \\
\text { homes } \\
\text { examined }\end{array}$} & \multicolumn{2}{|c|}{$\begin{array}{l}\text { Type of homes } \\
\text { (no.) }\end{array}$} & \multicolumn{2}{|c|}{ Total } \\
\hline & & $\begin{array}{l}\text { Apart- } \\
\text { ments }\end{array}$ & Houses & no. & $\%$ \\
\hline Seoul & 19 & 14 & 5 & 19 & 32.7 \\
\hline Incheon & 3 & 3 & 0 & 3 & 5.2 \\
\hline \multicolumn{6}{|l|}{ Gyeonggi } \\
\hline Paju & 1 & 0 & 1 & 1 & 1.7 \\
\hline Goyang & 3 & 3 & 0 & 3 & 5.2 \\
\hline Gimpo & 1 & 1 & 0 & 1 & 1.7 \\
\hline Anyang & 2 & 2 & 0 & 2 & 3.5 \\
\hline Gwangmyeong & 1 & 1 & 0 & 1 & 1.7 \\
\hline Seongnam & 3 & 2 & 1 & 3 & 5.2 \\
\hline Suwon & 1 & 1 & 0 & 1 & 1.7 \\
\hline Hanam & 1 & 1 & 0 & 1 & 1.7 \\
\hline Guri & 1 & 1 & 0 & 1 & 1.7 \\
\hline Uiwang & 1 & 1 & 0 & 1 & 1.7 \\
\hline Ansan & 1 & 1 & 0 & 1 & 1.7 \\
\hline Pyeongtack & 1 & 1 & 0 & 1 & 1.7 \\
\hline Subtotal & 17 & 15 & 2 & 17 & 29.3 \\
\hline \multicolumn{6}{|l|}{ Gangwon } \\
\hline Goseong & 1 & 0 & 0 & 0 & 0.0 \\
\hline \multicolumn{6}{|l|}{ Chungnam } \\
\hline Asan & 1 & 1 & 0 & 1 & 1.7 \\
\hline Cheonan & 1 & 1 & 0 & 1 & 1.7 \\
\hline Daejeon & 1 & 0 & 1 & 1 & 1.7 \\
\hline Subtotal & 3 & 2 & 1 & 3 & 5.2 \\
\hline \multicolumn{6}{|l|}{ Chungbuk } \\
\hline Chungju & 1 & 1 & 0 & 1 & 1.7 \\
\hline Cheongju & 1 & 1 & 0 & 1 & 1.7 \\
\hline Subtotal & 2 & 2 & 0 & 2 & 3.5 \\
\hline \multicolumn{6}{|l|}{ Jeonbuk } \\
\hline Jeonju & 4 & 3 & 1 & 4 & 6.9 \\
\hline Iksan & 1 & 0 & 1 & 1 & 1.7 \\
\hline Subtotal & 5 & 3 & 2 & 5 & 8.6 \\
\hline \multicolumn{6}{|l|}{ Jeonnam } \\
\hline Gwangju & 1 & 0 & 1 & 1 & 1.7 \\
\hline \multicolumn{6}{|l|}{ Gyeongbuk } \\
\hline Gumi & 1 & 1 & 0 & 1 & 1.7 \\
\hline Andong & 1 & 1 & 0 & 1 & 1.7 \\
\hline Daegu & 1 & 1 & 0 & 1 & 1.7 \\
\hline Gyeongju & 1 & 0 & 1 & 1 & 1.7 \\
\hline Subtotal & 4 & 3 & 1 & 4 & 6.9 \\
\hline \multicolumn{6}{|l|}{ Gyeongnam } \\
\hline Jinju & 1 & 1 & 0 & 1 & 1.7 \\
\hline Busan & 2 & 2 & 0 & 2 & 3.5 \\
\hline Total & 58 & 45 & 12 & 57 & - \\
\hline$\%$ & - & 78.9 & 21.0 & - & \\
\hline
\end{tabular}

rax and head. The behavior and nesting habits of $M$. pharaonis resemble those of T. melanocephalum, in that they are most active in kitchens and pantries.
One of the problems that have emerged from urbanization is the use of different habitats by a great variety of insects [14]. Urbanization has spread across the globe rapidly and has generated various health problems and urban pests. According to a report from the Ministry of Land, Infrastructure and Transport, Korea (http://onnora.kr), the rate of urbanization in Korea has risen drastically from $35.8 \%$ in 1960 to $90.6 \%$ in 2015 , and the census statistics of 2015 (http://kosis.kr) indicate that the metropolitan areas of Korea (Seoul, Incheon, and Gyeonggi-do) contain $49.5 \%$ of the total population, with apartments representing $59.9 \%$ of the housing and houses representing $40.1 \%$.

The present study indicated that $78.9 \%$ of the T. melanocephalum infestations occurred in apartments and $21.0 \%$ occurred in houses (Table 1), and $67.2 \%$ of the T. melanocephalum infestations in Seoul, Incheon, and Gyeonggi-do occurred in homes. These results suggested that a correlation exist between population density and housing type in urban environments.

The reason that higher rates of $T$. melanocephalum infestation are observed in metropolitan areas (Seoul and Gyeonggi-do) than in other provinces is that T. melanocephalum infestation is associated with higher population densities and greater densities of well-heated apartments.

T. melanocephalum cannot survive outdoors in colder climates, and in these regions, the species is only found in heated buildings and greenhouses [1]. In addition, T. melanocephalum prefers to live at $25-30^{\circ} \mathrm{C}$ and with a relative humidity of $96 \%$ but does well within a moderate range of these values [15]. In general, the nests of T. melanocephalum are situated in inaccessible, warm, and moist areas that are close to a food source. Typical nest locations include plant pots, wall voids, behind tiling, cupboards in kitchens and bathrooms, meter boxes, and plug sockets [16].

In the present study, $93.0 \%$ of the infestations were observed from September to May, whereas only 7.0\% were observed in the summer (June-August, Fig. 2). Most of the indoor T. melanocephalum infestations that were established in September persisted until May, and the ants seemed to prefer outdoor sites during the summer. This suggests that T. melanocephalum cannot survive the colder outdoor temperatures that occur from autumn to spring and that T. melanocephalum is well suited to living in homes in Korea.

Today, ants are adapted to city living. The chances of ants surviving transport have increased, owing to the greater speed of modern transportation. Moreover, the diversity of products 
has increased, as has the number of countries from which such products originate. Increased tourism plays a role, as well, because ants can easily hide in plant materials or penetrate package materials [17]. Recent reviews of T. melanocephalum have reported that the species is adapted to urban life [1]. In Korea, the extent to which the infestation of T. melanocephalum has spread remains unclear. It was possibly spread through the movement of infested goods, plant products, luggage, or clothing by international tourists.

Pest ants in the urban environment have a significant impact on both the quality of human life and public health. Pest management strategies are required for safe and effective control. The best approach for controlling T. melanocephalum at home is cleanliness, especially since the nests of T. melanocephalum are often hidden. If post-infestation control is necessary, the ant is susceptible to a number of oral and contact insecticides [2]. The treatment method is the application of highly attractive bait products, especially if the whole house block is treated [16].

The present study provided evidence that, even though $T$. melanocephalum has had little time to become established in urban homes, it is possible that the species could become an increasingly common indoor pest and that the species could, someday, be found in every home in the country. Accordingly, we conclude that native ants, such as T. melanocephalum, are potential indoor pests of homes in Korea. Further studies that focus on the ecological niches and pathogens of T. melanocephalum, especially those relevant to humans, are needed.

\section{ACKNOWLEDGMENT}

This study was financially supported by the Arthropods of Medical Importance Resource Bank, Institute of Tropical Medicine, Yonsei University College of Medicine, Seoul 03722, Korea.

\section{CONFLICT OF INTEREST}

We have no conflict of interest related to this study.

\section{REFERENCES}

1. Wetter JK. Worldwide spread of the ghost ant, Tapinoma melanocephalum (Hymenoptera: Formicidae). Myrmecol News 2009;
12: 23-33.

2. Nickerson JC, Bloomcamp CL, Pereira RM. Ghost ant, Tapinoma melanocephalum (Fabricius) (Insecta: Hymenoptera: Formicidae). UF, IFAS Extension 2015; 1-4.

3. Espadaler X, Espejo F. Tapinoma melanocephalum (Fabricius, 1793), a new exotic ant in Spain (Hymenoptera: Formicidae). Orsis 2002; 17: 101-104.

4. Klimes P, Okrouhlik J. Invasive ant Tapinoma melanocephalum (Hymenoptera: Formicidae): A rare guest or increasingly common indoor pest in Europe? Eur J Entomol 2015; 112: 705-712.

5. Fowler HG, Bueno OC, Sadatsune T, Montelli AC. Ants as potential vectors of pathogens in hospitals in the state of Sao-Paulo, Brazil. Int J Trop Insect Sci 1993; 14: 367-370.

6. Rodovalho CM, Santos AL, Marcolino MT, Bonetti AM, Brandeburgo MA. Urban ants and transportation of nosocomial bacteria. Neotrop Entomol 2007; 36: 454-458.

7. Pantoja LD, Moreira Filho RE, Brito EH, Aragão TB, Brilhante RS, Cordeiro RA, Rocha MF, Monteiro AJ, Quinet YP, Sidrim JJ. Ants (Hymenoptera: Formicidae) as carriers of fungi in hospital environments: an emphasis on the genera Tapinoma and Pheidole. J Med Entomol 2009; 46: 895-899.

8. Lyu DP. Taxonomic study on the poneromorph subfamilies group (Hymenoptera: Formicidae) in Korea. Korean J Appl Entomol 2008; 47: 315-331.

9. Yun YY, Ko SH, Park JW, Hong CS. Anaphylaxis to venom of the Pachycondyla species ant. J Allergy Clin Immunol 1999; 104: 879882.

10. Kim CW, Choi SY, Park JW, Hong CS. Respiratory allergy to the indoor ant (Monomorium pharaonis) not related to sting allergy. Ann Allergy Asthma Immunol 2005; 94: 301-306.

11. Bonnefoy X, Kampen H, Sweeney K. Public health significance of urban pests. Copenhagen, Denmark. WHO Europe. 2008, pp 347-374.

12. McMichael AJ. The urban environment and health in a world of increasing globalization: issues for developing countries. Bull World Health Organ 2000; 78: 1117-1126.

13. Collingwood CA, Tigar BJ, Agosti D. Introduced ants in the United Arab Emirates. J Arid Environ 1997; 37: 505-512.

14. Soares NS, Almeida Lde O, Gonçalves CA, Marcolino MT, Bonetti AM. Survey of ants (Hymenoptera: Formicidae) in the urban areas of Uberlandia, MG, Brazil. Neotrop Entomol 2006; 35: 324328.

15. Appel AG, Na JPS, Lee CY. Temperature and humidity tolerance of the ghost ant, Tapinoma melanocephalum (Hymenoptera: Formicidae). Sociobiology 2004; 44: 89-100.

16. Brooks MD, Nentwig G, Gutsmann V. Elimination of a Tapinoma melanocephalum (Hymenoptera: Formicidae) infestation using imidacloprid bait. Int Pest Control 2009, 240-243.

17. Boer P, Vierbergen B. Exotic ants in the Netherlands (Hymenoptera: Formicidae). Entomol Ber 2008; 68: 121-129. 